\title{
Triggering Intertext: Replacing Reality with Communication*
}

\author{
Ramil Karimov \\ Department of Social Philosophy \\ Peoples' Friendship University of Russia (RUDN University) \\ 6 Miklukho-Maklaya Street \\ Moscow, Russian Federation 117198 \\ E-mail: Karimovramil@gmail.com
}

\begin{abstract}
The following article describes some aspects of what it considers to be a new form of intertextuality and its effects on social life. Given that the world we live in today falls under the description of simulacra by $\mathrm{J}$. Baudrillard and the totality of the text by J. Derrida, but this text is not closed within its borders, as $R$. Barthes put it, and on the contrary, is opened and is being voluntarily interlined with other texts, which are produced and reproduced constantly by a great number of authors, what is made largely through the process of online communication, those interlinked texts come in such great numbers and across so many mediums or platforms that, as M. McLuhan put it, everything is happening simultaneously, one could argue that the reality as we know it, becomes surrounded or enhanced by this virtual reality of interlinked texts. And those processes are happening within the reality of texts, but at the same time are affecting our usual reality of people, even causing changes in social dynamics. So the new intertextuality is not only not staying within the borders of a single text, it's now not even staying within the borders of its own reality.
\end{abstract}

Keywords-intertext; virtualization; cross-platforming; triggering intertext; new intertext; communication; feedback; medium

\section{INTRODUCTION}

For the last 10 years, two major tendencies that are related to communication process, as well as social life as a whole, may be brought into the spotlight due to its pertinent nature: the first one we called the "triggering intertext" or the "new intertext" and the other - what is called by many as the "virtualization of social reality". The notion of the intertext is a post-structural term for the pre-existing plurality of the text, underlined by R.Barthes, as in terms of interpretations, as well as in terms of being always composed, at least partially, from the mixture of other texts [1]. The notion of text is taken here in its broad meaning, but not as broad as R.Barthes understood it. Barthes understood text as universal category which may signify even a whole culture, a country etc. In this article the text would be a steam of logically linked symbols, which translates human's thoughts through

*The publication has been prepared with the support of the "RUDN University Program 5-100". various mediums, not only written, but also through video, audio and other types of mediums. An intertext deals with a stream of linked texts. Y. Kristyeva called this notion the "intertextuality", underlining that any text is being composed of various citations-puzzles, the origin of which are very hard to find, giving its unconscious nature [2]. Every text is an intertext, composed of other texts that are there on various levels, being cited on an unconscious level, based on author's experiences. Understanding intertextuality this way, leads to the study of cultures. The alternate approach for understanding the intertextuality hides in G.Genette's interpretation of it, as one of subcategories of a larger term transtextuality, which means all intentional and unintentional relations of a given text with other texts [3]. So the other understanding of intertextuality is what N. Stepanova called a linguistic approach, which studies an intentional intertextuality through various markers [4]. A. Lahman also interpreted the intertextuality as a form of interaction between texts, labeled through various methods [5]. N.Bashirova enumerated some of them: citation, allusion, reminiscence, imitation and others [6]. So this intertext only served its author and was used only to enhance and enrich the existing text.

So, it might be derived from this that the intertext may come in two major forms - intentional and unintentional. However, what we call a "triggering intertext" is somewhere in between - it's intentionally building the string of intertexts to the point where they create some form of cultural reality. Something that was being done unintentionally before is being done intentionally today, and with a specific goal building its own reality of interlinked texts, thus virtualizing in some way the existing reality.

The virtualization of social reality in various forms was studied by numerous researchers within the framework of various theories - from the theory of Information society to the ideas of computer-generated virtual reality, as well as simulacra of J. Baudrillard and others [7]. Virtualization unites within itself other modern tendencies, like decentralization, growing value of knowledge and information, hybridization as among humans, as well as B.Wellman's system of interaction between a human and a machine reinforces stay-at-home social behavior due to the 
ability to communicate via mediums fast and avoiding social interaction within the reality [8].

Virtualization as a rapid and extensive growth of the predominant value of information, knowledge and communication over production of goods or economic exchange was vastly described within the theory of information society, which derived from theories of postindustrial society by D.Bell, A. Toffler, R.Touraine and others [9] [10] [11]. The idea of increasing value of knowledge being the driver of social and economic success was also studied by P.Drucker, who also underlined the tendencies of today's production, exchange and communication systems to become decentralized, segmented and simplified due to non-flexibility of large multi-structural systems, which are united by communication [12]. This point was also brought up by $\mathrm{M}$. Castells who claimed that the vertical structural models of the past cannot sustain the volume of information exchange and communication processes of today's world, thus giving way to social network models, which are more flexible [13]. Decentralization was also the key point in the philosophy of G.Deleuze and F.Guattari described as the "rhizome", which characterizes the non-hierarchical, horizontal types of connections and communications with no centralized entry points [14]. Mutualism as cooperation and synergy, as well as the hybridization are the core phenomenon's of today's social dynamics. Hybridization as the phenomenon of mixing various social constructs together, for instance $M$. Hardt and A. Negri argue that the modern systems are subjects to hybridization process, where everything is mixed with everything [15]. According to J. Baudrillard today's consumerism is leading to the state when the reality is being replaced with its simulations, things are replaced with its copies or its signs, symbols that signify the object but they are not the object [16]. Yet, they are trying to be. Through 4 stages of development of a sign, starting with a sign being a reflection of an object, thus making it a reflection of reality, to the last stage - simulacrum, non-related to the reality what so ever, is a pure reality of signs. Thus, hyperreality is replacing reality.

So, all these modern theories, as well as many others, in one way or another bring up the following point: reality of information and communication, basically the reality of what J.Derrida and R. Barthes called the "Text" is not only competing with the physical reality, but is trying to replace it in some way [17]. The totality of the text described by J.Derrida, when the text is representing the whole social reality, and the approach of McLuhan and H.Innis, where the development of communication capabilities frames social reality, and ways of social interactions influence the relations of power and economy in a society, may help to grasp changes born within the reality of texts, but affecting the reality of people [18] [19]. The problem is that this merge of the reality and the text is now being frozen in some state between the two. In one way we see the deconstruction of reality made by the text, on the other side - we see how the text is trying to replace the reality with constant communication made across different platforms simultaneously: internet and its social media, newspapers, books, TV, movies, comic books, advertisement - they are all coming together through various mediums and surround a human being, simulating the reality, thus trying to replace it with constant communication. But it is not the reality of many texts. Well, it is, but what gives the power to the text to be able to replace reality to a certain degree is not being just a bunch of disparate texts, but being the intertext - a long stream of texts. And one of major changes that happened in last 10 years in the reality of texts, affecting the reality of people, ways of social dynamics and interactions is the emergence of what we call - the "triggering intertext".

\section{The TRIGGERING INTERTEXT ACROSS DIFFERENT MEDIUMS}

The "triggering intertext" (or the "new intertext") is called this way because of its ability to trigger new waves of texts, to trigger a specific reaction and response from the reader. New waves of texts could be triggered as part of the direct response to this text, like a commentary feedback or as part of inspiration coming from consuming the text, like parody or imitation etc. This construct may be a relatively new one, but some rudimentary forms of it could be found in previous history of mankind's culture as well. However, today's world of multiplatform communication (production, transmission and reception of symbolic forms), made increasingly through mediums and virtual reality of the internet and its social networks gave birth to the "new intertext". So the text today is living in various forms and across various platforms - social media, film, audiotexts, radiotexts etc. And people are viewed less as an individual, but more and more as "readers" or "authors" of texts. So what are the difference between the intertext of the past and the interext of the now?

First of all - it's being done in the era of mass communication, where, as M.Mcluhan put it - everything is happening simultaneously, and also, everybody can create texts that would be red by the audience [20]. Before this, the reader was represented by mass majority and the author by a minority. Only author could create the text and the reader could only read it (generally speaking). But today, the difference between the author and the reader has been blurred out - the reader can quickly become the author, the author becomes the reader and this exchange of roles happens simultaneously for as many times as possible. The text is evolved from vertical communication from the author to the reader into more horizontal communication between various actors. So, creating a text to give a feedback on the original text has become a new way of communicating with the authors of the original text, as well as with the audience, as well as with thyself. The number of intertexts has grown spontaneously and intertextuality has become a new style of making the text for the reader.

Second of all - the new intertext is not being contained within one text, but within a line of opened texts, which also come across various platforms. Before, the text could be composed of various texts, but still stayed within the borders of it. Todays' intertext is triggering the creation of other texts, starting waves after waves of communication, and then quieting down in order to give way for the others texts to 
create new communication waves. The new intertext is not stopping at the borders of even few texts; it's trying to create a large web of interlinked texts - to make true the principle of "rhizome" of G.Deleuze and F.Guattari come to live.

Before today's world we also had some kind of pra-forms of making interlined texts, for example making a series of books about one or two main characters, like Sherlock Holmes by Ser Arthur Conan Doyle or the novels about Hercule Poirot by Agatha Christie. However, they had only one medium to convey the story - a book. So every intertextual element stayed within those books. Later on there were films and series created based on these characters - the intertextuality spreads. But it still didn't demand to consume the information through the alternate medium in order to understand what's going on in the text translated thought this given medium. The reader didn't need to read a book in order to understand the films and vice-versa. There were no other books by other authors that explained what was going on in the book.

The closer we get to the now, the more intertexts on more platforms by more authors are created. Retellings, explanations, the so-called fan fiction stories, drawings, adaptations, comic books, series, reimaginings with subtle nods to the original novel demand more and more to be invested in the text in order to understand it and also be part of the sub-culture, that is being created around this intertext. Today the best examples of this would be the famous comic book character created by world biggest Marvel and DC comics studious. They create unique characters on the pages of a comic book about this character (say "Spider-man" comics), but then bring him or her to other comic books about other characters (say "Fantastic four" characters). They interact with each other and events happen across multiple interlinked and cross-referenced texts. And in order to keep up with everything, a reader has to read all the other related texts. And today it happens not only in written form. DC studious created 3 different TV-series called "The Arrow", "The Flash" and "Supergirl". However, later on, all major characters from one series appeared in the others, making it obligatory to follow on a daily basis not one, but three series, which led to subsequent emergence of a new so-called profession - an internet critic/reviewer, who did this for other people who don't have time for it. But more on that later. What is also important to note that those texts are created using different mediums. They come across TV, comic books and the internet.

The intertext today doesn't content with citations, it fully intercrosses various texts of various formats. A video is crossed with a comic-book and a videogame, a book is crossed with articles on the internet, films, cartoons etc. The same old Marvel studios and DC comics' studios made a long string of films (for example, the Avengers, Iron man, Spider-man for Marvel studios and Superman, the Justice Leagues etc. for DC studious) that interact off each other and are interrelated with the comic books, the films themselves and also the series, and then they issue other comic books, based on the events portrayed in the films, thus making in a constant loop of self-sustaining texts. In order to understand it all, the creators make the reader to look for information across platforms, making it a hunt for knowledge, which is useless outside this world, created by intertextuality. The reader has too watch films, have read the comic books, watch the series and cartoons. For example, a videogame "The Injustice, Gods among us" demands from the player to read the comic book in order to know how begins the story, portrayed in the game. And then he the reader has to read another comic book to understand how the story continues. So it demands a constant shift across platforms in order to receive a full experience. So, the texts are intentionally created unfinished, opened only in order to continue making them through other mediums. And it's softly demanded from the reader to surround himself with this fictional world.

Cross-platforming allows creating an intertext, which becomes a jigsaw puzzle that needs to be reconstructed by the reader that according to $J$. Derrida is more creating a new text, rather than deconstructing the existing one [21]. But the original text itself is being deconstructed because of this. When the book is retold in a Youtube video, it's being deconstructed and reconstructed by the video's author. R.Barthes claimed that "the author is dead" [22]. Well, today it's even deader.

\section{DECONSTRUCTION AND TRANSCENDING TEXTS}

Whereas the original texts are created for ones mediums, such as books or films, the other texts about those original texts are created on other platforms, mostly on social media. A big wave of various authors with their personal input on the original text appeared relatively recently on the internet in order to comment, review, parody or explain the original text. They are creating transcending texts about this text. A book by one author could be reviewed in different ways across different platforms by different readers-authors (readers of the original texts and authors of their own texts, based on the original) - in newspaper articles, articles on the internet, Youtube videos, social media posts etc. Even in an interview with the author of the book, or actors of the film, which air on TV and Youtube and deconstructs the illusion of the original text by transcending it. The news about actors of the movie having difficulties with the director, or the information about a book not selling very well destroys the illusion that the text tried to create, and makes it part of our ordinary world. This manner of commenting on every text, showing what's been going on behind the scenes changes the way of consumption of texts. Now people got used to read the text in a deconstructed way. For instance, actors of movies become some kind of mediums as well, they contribute to the intertextuality even where the intertext wasn't possible. The actor who portrayed Harry Potter is being associated with this character no matter the movie he plays in. An actor who played Sherlock Holmes in "Sherlock" series also played Alan Turing in "The Imitation Game". The viewers couldn't shake the references and inside jokes of the series while watching the film.

The new intertext is being destructive to a given text because it's tearing it from the inside by being aware that it's being a text. The texts of today like to actively demonstrate that everything that's happening within the text is fictional. The texts are actively mocking themselves. For example, the 
movie "Avengers: Age of Ultron" issued in 2015 features a character that had been mocked on the internet for being quite useless. 3 years prior to the release of said movie, this point was vastly depicted in sketches, articles, songs, memes etc. Even the actor portraying the character actively partook in this process of ridiculing the character. So, the character was deconstructed by other texts, created on other platforms. And then within the film he was the one to jokingly acknowledge said uselessness and even further acknowledge quite the ridiculousness of the premise of the movie itself, while the film in general was taking itself rather seriously. The thing is that the text has deconstructed and criticized some part of itself before the reader could do that. The text did it for the reader, instead of the reader. Those kind of texts are now of growing popularity, they are cynical, they pretend to create an illusion, a story, but at the same time, they may deconstruct themselves to wink at the audience, to "show off".

But even more so, when the character of Sherlock Holmes made a subtle reference to "The Imitation Game" film during an episode of the "Sherlock" series, the authors of the series expected the audience to be having a specific reaction of excitement because the viewer could participate in reconstruction of this particular intertext. It's like the reader is participating in the text in some little way.

Those texts don't close the door to virtual reality they creating; they are leaving the door opened a little bit, so the reader couldn't forget that this text is tied to the reality. It doesn't try to emerge the reader full into the different reality; it's trying to enhance the existing reality with a text. But also remind the reader that he or she is a reader and invites to participate in the act of its performance. But participation of a reader went beyond participation only in the performance of the text, and now, through communication, mainly through the developed feedback option, the reader may even influence the text, the reader may say which texts he prefers to consume.

\section{THE FEEDBACK THROUGH THE NEW INTERTEXT IN A COMMUNICATION PROCESS}

The new intertext is becoming more and more about communicating directly with the audience using texts. The text is used and recreated and deconstructed during communication process between an author and a reader. It's not about transmitting some meaningful ideas by the Author (with a capital " $A$ " - this author is dead) and trying to understand and decode them by the reader, it's more about communication by an author (a secondary author who deals with an intertextuality, deconstructs and reconstructs the text, who is actually better be called a communicator) and the reader. It's more about communication about the text, when the text itself, as well as the original Author, is basically dead, they are not really essential to this process; the text is just the topic of a conversation. It's not the text; it is the communication what matters today. And today's communication has the intensity and broadness of feedback that has never been before.
The Osgood-Schramm communication model depicts a feedback as a paramount detail in communication process, which wasn't considered by the linear models of communication prior to this theory [23]. The audience is inevitably giving some kind of feedback to the author, but it's not always possible for this feedback to reach him. However, in the world of today, the feedback is given through adding to the original texts, thus creating a loop on intertexts and so communicating though them. This feedback allows even to affect the parts of the intertext. When first text of a larger intertext comes out, the readers are able to give a feedback. And when the next text comes out, it's likely to be altered by this feedback. A bright example of this kind of feedback happened with Sir Arthur Conan Doyle, when readers had been actively asking him to revive the loved Sherlock Holmes character, which was killed off in the "The Final Problem" story, which he eventually did in "The Adventure of the Empty House" story. This was done through interpersonal communication between the readers and the author. But the texts themselves weren't the part of mass communication, nor even intragroup communication. Today we see exactly this. Even it's possible to write the author as part of interpersonal communication, the feedback is also given by creating other mass-communicated texts.

Modern movies, given their intertextal nature are likely to be affected by this. For instance, internet user's complaints about the movie's "Man of steel" issued in 2013 total lack of empathy for victims and an enormously large scaled destructions depicted in the movie affected the next film in the series - "Batman V Superman: Dawn of Justice" issued in 2016. The next movie didn't have those issues, however made them in a way that almost directly told the audience that their wish was granted. So today's world of intertext creates an opportunity for the readers to participate in collective creation process. So today there is no one author anymore, there are many. And the text is now more and more born within communication and for communication, which means it is not created - it's made through construction, deconstruction and reconstruction and the feedback.

\section{Shifting Social Statuses of Authors}

The triggering intertext is very strongly oriented towards triggering a specific reaction in a reader which relates to possessing certain knowledge, acquired through other platforms and other texts that made part of this particular text. And acquisition of this knowledge, according to P. Drucker and E. Toffler is being the driver of social and economic success of the world we live in today. Knowledge creates a sense of elitism for those who understood the given reference. In pop-culture of the social media there is even a somewhat vulgar term for this - a nerdgasm. If there is a term, there is a social phenomenon behind it. Nerdgasm is composed of two words and means a sensation of rapture evoked in a person because of understanding a certain reference to what is called a culture of nerds or geeks (people who are passionate about some intellectual activity or cultural phenomenon, often perceived as socially awkward, boring or peculiar). But the problem is that it is not the knowledge related to a real world, but it is knowledge related the world of fiction, the world of 
intertextuality. However, the shifts in social status of certain people are quite real.

According to B.Wellman, the mediated communication is replacing real-life communication, enforcing individualism and perceiving every communication as a person-to-person communication [24]. The communication mediated by the internet allows to make personal communication not only with one or several friends, as in real life but with larger groups and to build social connections with strangers as if it was an interpersonal communication. So, every communication is perceived as personal, thus creating a feeling of possessiveness in relation to some intertext. One could even argue that intertexts of today received kind of a "sacred" status. They are worshiped; they have a large group of fun-followers, who are very eager and even prone to violence.

$\mathrm{Ph}$. Tagirov argues that today's world has a tendency to declare a mundane value as unifying principle; and around those values conflicts of interests are build, which may fuel other conflicts and continue to follow this path [25]. Today's civilization being the civilization of voyeurism finds pleasure in consuming information depicting violence. Through the computer screen violence becomes even more symbolic and virtualized than before, making it easier to accept it and then to translate it further. However, given the virtualization of said process, violence is also transmitted using texts, mostly through means of communication. Such social problem as cyberbullying were unheard off only two decades ago, but today became one of pertinent problems in society that need to dealt with, because new ways of effectuating domination and relations of power through means of cyber-violence emerged.

Moreover, understanding the intertextual references has become some type of profession. Even 10 years ago a subculture of geeks was just that - a subculture, but today this situation has changed. This emergence of this subculture is starting to dominate to some level the pop-culture of youngsters today. Given that the emergence of the intertextuality is related to this sub-culture, it shifted social status of those so-called nerds or geeks and made them the opinion leaders, because they possess one important thing knowledge. And they share this "sacred knowledge" through creation of their intertexts and then made this their profession. So a few years ago we've already witnessed the emergence of this new profession - they explain, decode, review and parody the original text. Those who considered having "useless hobbies" are now "the ones who possesses knowledge". And it's mostly them who may affect a given intertext creation process by giving a "loud" feeback. Even more so, they are making videos on Youtube, or articles on the internet titles "things we want in a $\mathrm{X}$ (movie, game, book etc.)". So they are trying to actively influence the text creation process while it's being constructed. Thus, they are trying to implement the principle of what M.Zelenov called the preliminary censorship when the content of the text is being controlled before its publication [26]. Normally, this type of control is effectuated by the State. However, these authors also try to make it so - to effectuate control over the text that doesn't belong to them.

\section{CONCLUSION}

Development, evolution and diffusion of mediums thought society indubitably changed ways people interact with texts. A now as the post-industrial society progresses, a great number of mediums, which are largely interlinked amongst them, is constructing a new virtual reality of the totality of the intertext. The new intertext surrounds people through creating a possibly endless stream of interlinked texts. Whether the reality of intertext and communication is replacing the reality of just trying to merge with it in order to enhance it, is a question up for debate and depends on to what degree we consider reality to be "real" and the text being "virtual". However, there is a finite number of things a human being can do in a given timeframe, and there is finite number of information a brain is able to process, so, when the intertext surrounds people through mediums of communication and there is no escape from this endless intertext, there's going to be a tension. Because a choice has to be made, whether the knowledge about the real world, or the knowledge about the fictional one is of importance. Knowledge about fictional doesn't demand only to know one text, it demands to know a lot of them. And even large number of communities arises around those texts. So human life in a society today becomes more and more about communication through intertext and about intertexts and is more and more effectuated through mediums, and becomes less and less about real life issues and situations or economy or production, and is less and less effectuated without using any medium. So, today we see only the beginning of this process, but it's hard to tell right now whether it's just a phase, which will fade quickly after the majority of people loses interests in consuming such large amount of interlinked texts with no purpose, or gets tired of being constantly "attacked" by the texts from every corner, or whether we witness the emergence of a new form of social dynamics, which will stay with us for a long time.

\section{REFERENCES}

[1] R.Barthes, "Selected works: Semiotics: Poetics: the translation from French/edition by G.K. Kosikov". Moscow: Progress, 1989.

[2] Y.Kristyeva, "Selected works: the destruction of poetics". Moscow: Rosspen, 2004.

[3] G.Genette, "Paratexts. Thresholds of interpretation". Cambridge: the Press Syndicate of the University of Cambridge, 1997.

[4] N.Stepanova, "Intertextuality in cultural texts". Moscow: Teacher the XXI century №3, 2012, pp. 360-363.

[5] N.Petrova, O.Kulakova, "Various approaches to determining intertextuality". Irkutsk: bulletin of the Irkutsk State Linguistic University, 2011, pp. 131-136.

[6] N.Bashirova, "The typology of intertexts in the press". Kazan Scientific Notes of Kazan University. Humanities series, vol. 153, book 6, 2011, pp. 191-203.

[7] J.Baudrillard, "The system of objects". London: Verso, 1996.

[8] B.Wellman, "For a social network analysis of computer networks: a Sociological Perspective on Collaborative Work and Virtual Community". Toronto: Centre for Urban and Community Studies, Univ. of Toronto, 1996

[9] D.Bell, "The Coming of Post-Industrial Society: A Venture in Social Forecasting". New York: Basic Books, 1973.

[10] A.Toffler, "The third wave", New York: Bantam Books, 1980. 
[11] R.Touraine, "The Post-Industrial Society. Tomorrow's Social History: Classes, Conflicts and Culture in the Programmed Society". New York: Random House, 1971.

[12] P.Drucker, "Landmarks of Tomorrow: A Report on the New Post Modern World”. New-York: Harper and Row, 1957.

[13] M.Castells, "The Internet Galaxy: Reflections on the Internet, Business, and Society". New-York: Oxford University Press, 2001.

[14] P.Grechko, "Rizoma as a metapattern of history//conceptual models of history". Moscow: Logos, 1995.

[15] M.Hardt, A.Negri, "Empire", Moscow: Praxis, 2004.

[16] J.Baudrillard, "Simulacres et simulation". Paris: Galilee, 1981.

[17] G.Hendricks, "Deconstruction the end of writing: Everything is a text, there is nothing outside context". South Africa: AOSIS, 2016.

[18] M.McLuhan, E.McLuhanan, "Laws of Media: The New Science". Toronto: University of Toronto Press, 1992.

[19] S.Volodenkov, "Communication theory of H.A.Innis and modern information and communication technologies: political analysis". Moscow: Socio-political science, 2011.

[20] M.Mcluhan, "The Gutenberg Galaxy: The Making of Typographic Man". Toronto: University of Toronto Press, 1962.

[21] J. Derrida, "Writing and difference". Chicago: University of Chicago Press, 1978.

[22] R.Barthes, “Image Music Text”. London: Fontana Press, 1977.

[23] O.Ivanova: "Transformation of communication as anything goes". Moscow: Society and power №2, 2014, pp.7-11

[24] B.Wellman, "Little Boxes, Glocalization, and Networked Individualism". Toronto: Centre for Urban \& Community Studies, University of Toronto, 2001.

[25] Ph. Tagirov, "Symbolic Violence and the Other in Cross-Cultural Field", Proceedings of the 2016 International Conference on Arts, Design and Contemporary Education (ICADCE 2016), Paris, Atlantis Press, 2016, pp. 1268-1273. doi:10.2991/icadce-16.2016.310

[26] M.Zelenov, "Censorship: approaches to the definition of the concept", Saint-Petersubrg: Leningrad Law Journal, 2013, pp. 94-103. 